is that whenever in doubt authors should ask the editor in a covering letter about possible dual publication, enclosing copies of previous articles that might be regarded as prior or duplicate publication.

Nevertheless, when any further publication would be merely repetitive editors are unlikely to accept the article; one of their functions as gatekeepers to the scientific literature must be to prevent worthless additions to it. In particular, I believe that the practice of publishing almost identical articles in supplements reporting conference proceedings as well as in main line scientific journals must stop. Authors must decide where they wish their articles to appear, editors must be harsh, and conference organisers must accept that contributors have a right to refuse publication of their work in conference proceedings.

An exception to such a hard line may be publication in another language, often directed at a different group from the initial publication. This will ensure that first class work will be reported in its country of origin as well as to a worldwide audience. The important principles behind such "parallel" publication-so named in a recent statement by the Vancouver group to distinguish it from "repetitive" publication" are that both editors agree to it; the priority of the primary publication is established; a footnote in the second article ensures that the reader and the indexer are left in no doubt that the primary publication was in another, named journal; and that in their curricula vitae authors do not quote both articles as separate pieces of work.

This final provision underlies the role that readers, and particularly members of appointments committees and academics, might have in bringing repetitive publication to light and in exposing its perpetrators to the ridicule of the scientific community. For example, before an important appointments committee the late Professor John Squire was said to have spent the previous day in the library skimming through the publications of the principal candidates, and woe betide anyone who had spread his work thinly over a large number of articles or had published the same work in more than one journal. In the long run such action might be better than the sanctions proposed by several American editors-for example, the refusal for three years to consider any manuscripts submitted by a certain author who had published similar articles in Cell and Proceedings of the National Academy of Sciences, ${ }^{1}$ or informing the principal of the institution and a grant giving body that an author supported by them has practised repetitive publication (private information). Editors should also play a part in such action, however, and in future we plan to inform Index Medicus and to print a prominent statement on the following lines drawing attention to the instance.

"Notice of inadvertent repetitive publication: The BMF regrets that the article entitled 'Use of lasers in pinealology' by AC Block and YZ Tackle of the Medical College of the University of the Scillies (30 February 1983, p 1937) was substantially the same as 'Pinealology and laser use' by YZ Tackle and AC Block published in the British Fournal of Pinealology (1983;18:122-8). The authors hold sole responsibility for this action, which is in violation of accepted scientific ethics and of the BMf's Instructions to Authors."

Editor,

STEPHEN LOCK

British Medical fournal
1 Abelson PH. Excessive zeal to publish. Science $1982 ; 218: 954$.

2 Anonymous. Instructions to authors. [Editorial.] $\mathrm{Br} M e d \mathcal{7} 1984 ; 288$ :6.

3 International Committee of Medical Journal Editors. Uniform requirements for manuscripts submitted to biomedical journals. $\mathrm{Br} \mathrm{Med} \mathcal{f}$ $1982 ; 284$ : 1766-70.

4 Anonymous. Definition of "sole contribution." [Editorial.] $N$ Engl $\mathfrak{f}$ Med $1969 ; 281: 676-7$.

5 Relman AS. The Ingelfinger rule. $N$ Engl f Med 1982 ;305:824-6.

\section{Seat belt success: where next?}

The end of January saw the completion of the first 12 months of compulsory wearing of seat belts in the front seats of cars in Britain - a remarkable success story in road safety legislation. Front seat belts are now used by around $95 \%$ of drivers in Britain. ${ }^{1}$ Fatal and serious injuries to occupants of front seats in cars and light vans have each fallen $25 \%$ overall-when the first eight months after legislation (February to September 1983) are compared with the corresponding period in 1982. This fall amounts to a saving of 350 lives and 4500 serious injuries.

An interim review of a survey in 15 hospitals of injuries experienced by surviving car occupants is to be presented at the annual meeting of the Casualty Surgeons' Association in Edinburgh on 24 April (W M Rutherford, personal communication). It will be surprising if this study fails to confirm the findings of numerous other worldwide studies which have shown a substantial reduction in serious injuries, especially to the head and chest, after legislation on seat belts. ${ }^{2}$

The encouraging progress so far has prompted a group of six members of Parliament to table an early day motion in the House of Commons, which reads: "That in view of the success of the legislation requiring the use of front seat belts in cars and bearing in mind that mounting points for rear seat belts were introduced in 1981, this House believes that it is now time for rear seat belts to be fitted in new cars." (27 January 1984.)

Some amendments have been proposed to this motion, including one which requires the wearing of seat belts by passengers in the rear seats to be mandatory. Mr Barry Sheerman, MP, chairman of the Parliamentary Advisory Council on Transport Safety, however, believes that legislation is best taken one step at a time. Members of Parliament and members of the public are likely to object if too much haste is made towards the ultimate conclusion of seat belt legislation-which is the safe carriage of all car occupants all of the time.

Legislation for rear seat belt usage makes good sense for three compelling reasons. Firstly, it will save the lives of around 135 rear seat occupants a year. ${ }^{4}$ Secondly, it will prevent the rear occupant acting as a missile which may kill or seriously injure the front seat occupant. Possibly $6 \%$ of fatally injured front seat occupants' lives might be saved by this means. ${ }^{4}$ Thirdly, the provision of rear seat belts when combined with a booster cushion will allow an easy and cheap solution for the safe carriage of all except the very youngest children in cars. Many parents fail to use safety devices for their children because of the expense, inconvenience, and hassle of fitting harnesses or bucket seats. ${ }^{56}$

Those arguing the case for further legislation are not just considering the humanitarian aspects of saving life and serious injury: a reduction in the demand on NHS beds by victims of acute trauma will allow quicker treatment for patients on the long waiting lists for conditions such as hernia and hip replacement. Road casualties take up many of the beds on surgical and orthopaedic wards. They often require lengthy admission 
and prolonged rehabilitation. The estimated overall savings on accident costs from the first year of seat belt legislation is of the order of $£ 120$ million-enough to finance the running of four whole health districts for one year. ${ }^{7}$

We need to remember, however, that wearing seat belts by all occupants of motorcars is only a form of secondary prevention in that it reduces the severity of injury after the accident has happened. More attention needs to be paid to primary prevention-in the form of improving the behaviour of drivers and especially in discouraging them from drinking and driving.

Members of Parliament welcome expert advice and informed comment, especially when these are based on sound evidence. The doctors' lobby was an important factor in the first stage of seat belt legislation. Should the BMA now adopt the next step as part of its policy? And should doctors lobby their own local members of Parliament to prompt them to support the early day motion?

J G AvERY

District Medical Officer,

South Warwickshire Health Authority,

Warwick CV34 4DE

${ }_{1}$ Department of Transport. Road accidents and casualties in Great Britain. Bulletin No STC 4 (84) 1. (Also reported in Hansard 1984 Jan 16;446: cols 836-9. (No 56.))

2 Bérard-Andersen $\mathrm{K}$. Use and effects of seat belts in 21 countries. Oslo: Institute of Transport Economics, 1978.

${ }^{4}$ Griffiths DK, Hayes HRM, Gloyns PF, Rattenbury SJ, Mackay GM. Car occupant fatalities and the effects of future safety legislation. In: Proceedings of the 20th STAPP car crash conference, Dearborn, Michigan, 1976. Warrendale, New York: Society of Automotive Engineers, 1976. (SAE paper 7670811.)

${ }^{5}$ Boughton CJ, Johnson IR. The effects of radio and press publicity on the carriage of children in cars. In: 1979 SAE congress and exposition, Detroit, USA. Melbourne, Australia : Office of Road Safety, Department of Transport, 1977. (Mimeograph.)

${ }^{6}$ Reisinger KS, Williams AF. Evaluation of programs designed to increase the protection of infants in cars. Pediatrics 1978;62:280-7.

${ }^{7}$ Anonymous. Rear seat belts. Br Med $\mathcal{F} 1984$;288:409.

\section{Mortality and morbidity among the old}

Today there are two and a half times as many people aged over 85 as there were 30 years ago. The size of this age group will continue to increase throughout the rest of this century whether or not death rates among the very old continue to fall. Those aged 85 spend on average 12 days a year in hospital, compared with under one day a year for nearly all those aged under 55 and just over two days a year for those aged 65 . Providers of health and social services expect that this increase in the number of very old people will place further pressure on already inadequate resources. ${ }^{1}$

In 1980 Fries presented a more optimistic view of the future. ${ }^{2} \mathrm{He}$ argued that the upper limit to the human life span was biologically fixed at about 115 and that the average life expectancy was unlikely to exceed 85 . Advances in the prevention and treatment of disease, particularly through changes in health related behaviour, would delay the onset of morbidity but would not affect the length of life. The number of very old people would stop increasing, morbidity would be compressed into a shorter period before death, and the need for medical resources would be reduced. Death would result from the biological process of aging rather than from a specific disease. In this society, which Fries thought was fast approaching, the survival curve would assume a "rectangular" shape. A near horizontal line depicting the low mortality up to about 85 would be followed by a sharp drop at the age of "natural death."

The concept of a fixed limit to the human life span, central to the Fries hypothesis, is not new. ${ }^{3}$ To support this, Fries cited Hayflick's demonstration of the finite capacity of certain cultured cells for in vitro replication. ${ }^{4}$ Hayflick suggested that this limit was not reached by cells in vivo, but that other functional losses occurred before replication stopped.

Fries's reliance on Hayflick's work, and the inferences that he draws from it, have been criticised. ${ }^{5}$ Fries noted that there had been no increase in the number of centenarians and used this as further support for his case. He also argued that aging is associated with progressive loss of organ reserve, eventually resulting in death, and that the Gompertz law of exponential increases in mortality with age was the statistical model which best reflected this biological process. ${ }^{6}$ Nevertheless, the Registrar General of England and Wales has recently shown that those born in 1880 were four times as likely to reach the age of 100 as those born just 30 years earlier, and that the Gompertz law does not adequately describe mortality patterns at advanced ages. ${ }^{7}$

The evidence in favour of a fixed limit to the life span is far from conclusive, but even if the hypothesis is accepted it is not clear how relevant it is to issues of immediate concern. Benjamin pointed out that no one has yet lived in an environment allowing aging unaffected by diseases of external origin. ${ }^{8}$ Persisting mortality differentials suggest plenty of scope for further improvements and, although the incidence of some chronic diseases seems to be falling, ${ }^{9}$ others are on the increase. Successes in disease prevention may yet turn out to affect biological indices of aging: smoking, for example, seems to be associated with an earlier age of the menopause. ${ }^{10}$

Many of Fries's predictions rely not just on an upper limit to the life span but also on an "ideal average life span" of 85 . To arrive at this figure Fries made a calculation from past trends in mortality which entails assuming that, given an overall level of mortality, there is a fixed relation between death rates at different ages. He also had to assume that at some stage deaths between birth and the age of 65 are eradicated. The first of these assumptions is known to be false $\mathrm{e}^{11}$; the second, most would agree, is distinctly improbable.

Fries is correct that falls in mortality have been proportionately greatest among the young and have progressively declined with age. This does not mean that there have been no changes in mortality at older ages. Investigation of mortality trends among the very old is hampered by problems of data. In England and Wales inflation of age at a census was a serious problem until well into this century ${ }^{12}$; problems at extreme ages still persist. ${ }^{7}$ Ages recorded on death certificates are generally more accurate, ${ }^{13}$ resulting in errors in the calculation of death rates due to the incompatibility of numerator and denominator. Investigators who have devised methods of dealing with these problems have all reached the same conclusionnamely, that there has been a real and significant fall in mortality even among those aged over 85 . In America the recent percentage falls in mortality in this age group exceed those in all other age groups over 25.14-16 Manton found no indication that mortality rates among the very old were reaching a ceiling. ${ }^{17}$

The figure shows percentage changes in death rates at various ages in England and Wales since 1891-1900. There have been fairly sizable falls in the mortality of the oldest age groups, and these show no sign of levelling off. Between 